\title{
LAYANAN REFERENSI \\ DI PUSAT PERPUSTAKAAN \\ UIN SYARIF HIDAYATULLAH JAKARTA
}

\author{
Oleh: Maryulisman
}

Abstract

\begin{abstract}
This paper discusses about Reference Service at Central Library of State Islamic University, The objective of this article is to describe the practices of reference services and the barriers in delivering the services. Based on the study it was found that the reference service doesn't function properly either in the type of the service or the service system provided. The service system is offered manually. Moreover, the competencies of reference librarians are still unsufficcient, particularly the competency of Arabic proficiency. It can hinder considerably in delivering reference services effectively.
\end{abstract}

Keywords: reference service barriers, delivering service, reference librarian competencies

Abstrak

Tulisan ini membahas Layanan referensi di Pusat Perpustakaan UIN Syarif Hidayatullah Jakarta. Tujuan dari tulisan ini adalah memberikan gambaran tentang pelaksanaan layanan referensi serta kendala-kendala yang dihadapi dalam pemberian layanan referensi di Pusat Perpustakaan UIN Syarif Hidayatullah Jakarta. Berdasarkan studi yang dilakukan layanan referensi di Pusat Perpustakaan masih terbatas atau masih belum berfungsi secara maksimal baik jenis layanan yang ditawarkan maupun sistem layanan yang sediakan. Sitem layanan yang diberikan masih bersifat manual. Selain itu, kompetensi yang dimiliki oleh pustakawan referensi belum cukup memadai. Kompetensi dalam penguasaan bahasa asing terutama penggunaan bahasa Arab menjadi kendala dalam menggunakan bahan-bahan referensi berbahasa asing.

Kata Kunci: layanan referensi, rerpustakaan perguruan tinggi

\section{A. Pendahuluan}

Pusat Perpustakaan UIN Syarif Hidayatullah Jakarta sebagai salah satu perpustakaan diantara beberapa perpustakaan fakultas yang ada di lingkungan UIN Syarif Hidayatullah Jakarta. Pemustaka yang mencari informasi ke Pusat Perpustakaan UIN Syarif Hidayatullah Jakarta tentunya berasal dari mahasiswa berbagai fakultas. Ini berarti koleksi layanan referensi yang disediakan oleh Pusat Perpustakaan UIN Syarif Hidayatullah Jakarta lebih beragam.

Seorang pustakawan referensi dituntut untuk dapat melayani kebutuhan pemustaka. Koleksi yang berada di Bagian Layanan Referensi Pusat Perpustakaan UIN Syarif Hidayatullah Jakarta antara lain berupa biografi, Bibliografi, sumber geografi, indeks, abstrak, direktori, kamus, ensiklopedia dan almanak. Sumber-sumber koleksi layanan referensi tersebut menggunakan bahasa Indonesia, bahasa Inggris dan bahasa Arab.

(Alfons dkk, 2014) Perguruan tinggi adalah lembaga pendidikan tinggi, yang berjalan secara sistematis dan terencana dimana terdapat suatu proses kegiatan dengan masyarakat ilmiah didalamnya. Pendidikan tinggi merupakan 
tempat untuk mempelajari, menggali, mengkaji atau meneliti dan mengembangkan ilmu secara bebas dan objektif. Dalam Undang-Undang Sistem Pendidikan Nasional No. 20 tahun 2003 disebutkan bahwa setiap satuan pendidikan formal dan non formal menyediakan sarana dan prasarana yang memenuhi keperluan pendidikan sesuai dengan pertumbuhan dan perkembangan potensi fisik, kecerdasan intelektual, sosial, emosional dan kejiwaan peserta didik. Perguruan tinggi sebagai wahana ideal untuk menciptakan masyarakat belajar perlu adanya perpustakaan sebagai suatu unsur penunjang tercapainya tujuan perguruan tinggi. Perpustakaan merupakan bagian intergral dari sebuah lembaga pendidikan yang menyediakan informasi bagi para pemakai khususnya mahasiswa, hal tersebut sesuai dengan Tri Dharma Perguruan tinggi yaitu pendidikan, pengajaran, penelitian dan pengabdian kepada masyarakat. Kemudian Pengguna perpustakaan adalah faktor utama dalam kegiatan jasa referensi. Pengguna dapat dikatakan sebagai orang yang berhubungan dengan menyediakan koleksi referensi. Koleksi referensi terdiri dari berbagai jenis seperti kamus, ensiklopedi, tesis, karya ilmiah, bahan ajar, laporan penelitian, laporan akhir, disertasi, jurnal dan juga majalah. koleksi ini digunakan oleh mahasiswa untuk kebutuhan informasi dasar seperti arti sebuah istilah, uraian suatu pengertian, alamat orang atau instansi serta data statistik tertentu.

\section{B. Pengertian Layanan Referensi}

Suharyanto dalam buku Glosarium Istilah Perpustakaan menyebutkan bahwa layanan referensi adalah semua kegiatan yang dilakukan oleh pustakawan referensi untuk memenuhi kebutuhan informasi pemustaka (secarapribadi,melaluiteleponatauelektronik) tidak terbatas untuk menjawab pertanyaan substantive, memberikan pengajaran kepada pemustaka dalam menyeleksi, menggunakan ala-alat dan strategi penelusuran yang sesuai untuk menemukan informasi, melakukan penelusuran dalam rangka memnuhi kebutuhan pemustaka, mengarahkan pemustaka ke sumber daya perpustakaan, membantu dalam evaluasi informasi, merujuk pelanggan pada sumber daya di luar perpustakaan, membuat statistic referensi dan berpartisipasi dalam pengembangan koleksi referensi.

Layanan informasi dan referensi diperlukan diperpustakaan karena banyak cara mengakses informasi di perpustakaan yang memiliki koleksi yang beragam. Meskipun pengorganisasian koleksi perpustakaan dianggap mudah oleh pustakawan namun bagi pemustaka tentunya pengorganisasian koleksi tersebut menjadikannya sulit dalam menemukan informasi yang dibutuhkannya. Untuk menjembatani antara pemustaka dengan sumber informasi yang ada di perpustakaan diperlukan layanan informasi dan referensi.

\section{Tujuan Layanan Referensi}

Tujuan pelayanan referensi adalah untuk memenuhi kebutuhan pemustaka mencakup mencari informasi dan menggunakan sumber informasi yang ada di perpustakaan. Seorang staf referensi perlu memahami bahwa meja informasi adalah bagain penting sebuah perpustakaan. Pelayanan yang diberikan di meja informasi berbeda bergantung dari jenis perpustakaan, sumber yang ada, dan staf.

\section{Jenis Kegiatan Layanan Referensi}

Jasa rujukan dibagi atas tiga kelompok besar, yaitu:

1. Jasa dasar yang mencakup: Pemberian informasi umum, penyediaan informasi khusus, bantuan dalam menelusur dokumen, bantuan dalam menggunakan katalog, dan jasa bantuan menggunakan buku rujukan.

2. Jasa yang lazim dilaksanakan, antara lain: Pinjam antar perpustakaan, tendon (reservation) buku, orientasi perputakaan, instruksi bibliografi, kunjungan perpustakaan, menyelenggarakan pameran termasuk pameran buku yang baru diterima, memberikan izin sementara bagi pemakai bukan anggota perpustakaan, membantu penerbitan perpustakaan, jasa bimbingan pembaca, jasa pengindeksan dan abstrak, kompilasi bibliografi, 
pembuatan kliping, pembuatan jajaran vertikal berisi pamflet prospektus, brosur, dan sebagainya.

3. Jasa yang jarang dilakukan antara lain: Pameran majalah mutakhir, pembentukan jajaran khusus seperti jajaran berisi kegiaan dan peristiwa mutakhir atau surat menyurat masa lalu dari badan induk, reproduksi dokumen, jasa terjemahan, jasa referal

Disamping tugas di atas, bagian referensi juga masih memiliki fungsi lain seperti: Pemilihan buku, mengolah tesis dan disertasi, mengawasi katalog perpustakaan, mengawasi pengembalian buku referensi ke rak, penjilidan, dan kegiatan lainnya.

American Library Association - Reference Service Division menyatakan ada dua jenis jasa rujukan yaitu jasa langsung dan tidak langsung. Pada jasa rujukan langsung, bantuan personil langsung diberikan pada pemustaka artinya pustakawan langsung membantu pemakai mencari informasi. Bantuan ini dapat berupa instruksi pemakaian perpustakaan dan memberikan informasi yang diperlukan pemustaka. Jasa referensi tidak langsung dapat berupa penyusunan katalog, bibliografi, bantuan rujukan lainnya, pemilihan dokumen, penyusunan bagian referensi, pembuatan jajaran informasi relevan, serta berbagai fungsi lain seperti fotokopi, pengawasan ruang baca, pinjam antar perpustakaan, dan sebagainya.

\section{E. Evolusi Pelayanan Referensi}

(Rosa, 2012) Dengan digunakannya teknologi informasi di perpustakaan, kebanyakan perpustakaan masa kini adalah lembaga hibrida yang menyimpan dokumen digital maupun tradisional atau tercetak. Dalam keadaan seperti ini, pustakawan referensi akan memainkan perannya sebagai navigator, yang akan menemani dan membimbing pemustaka untuk mendapatkan sumber informasi yang bermanfaat membuka cakrawala pengetahuan luas tanpa batas. Para pemustaka akan senantiasa memerlukan bantuan dan bimbingan pustakawan referensi dalam menenggarai sumber informasi yang paling tepat.

Teknologi memungkinkan kita mengakses sumber informasi yang berada di luar perpustakaan dan memberikan cara yang lebih mudah, konsekuensinya pustakawan harus tetap memainkan perannya sebagai manager informasi dan memberikan pelayanan informasi yang terbaik. Koleksi dan pelayanan perpustakaan akan lebih mudah digunakan, dan perpustakaan akan selalu berusaha memberikan nilai tambah informasi yang diperlukan pemustaka pada sumber yang tersedia yang dikelola dengan baik.

(Hildawati Almah, 2013) Awal Pelayanan referensi maya diluncurkan pada pertengahan 1980-an, terutama oleh perpustakaan akademis dan medis, dan disediakan melalui surel. Penerapan awal ini berdasarkan dua alasan, pertama untuk memperpanjang jam layanan bahwa pertanyaan dapat dikirimkan ke meja referensi, dan untuk menggali potensi jaringan kampus yang pada waktu itu menggunakan teknologi baru . OCLC (2007) On-line Computer Library Centre merumuskan bahwa referensi maya adalah pelayanan referensi yang menggunakan teknologi komputer dan komunikasi untuk memberikan pelayanan referensi kepada pemustaka kapan saja dan dimana saja.Pelayanan referensi secar digital adalah sebuah pelayanan pada perpustakaan yang dilakukan secara online (terpasang) dan traksaksi referensi dikomunikasikan dengan media computer.Hal ini dilakukan agar pelayanan referensi tidak saja terbatas pada waktu dan tempat tertentu.pemakai dapat melakukan konsultasi melalui email dari rumah atau tempat kerja dan tempat lainnya. Di samping itu, pelayanan referensi secara digital akan lebih cepat jika dibarengi dengan adanya kemampuan SDM dibidang Teknologi informasi. Bentuk-bentuk Pelayanan 1. Email 2. Webforms 3. Chat Using commercial applications

(Cassell dan Hiremath, 2011) Layanan referensi tatap muka telah mengalami penurunan setelah internet menjadi bagian utama dalam kehidupan pemustaka. Perpustakaan juga mencatat penurunan pertanyaan referensi dan peningkatan pertanyaan yang lebih rumit. Pemustaka hanya berkonsultasi kepada pustakawan referensi setelah tidak berhasil memperoleh 
informasi dari internet. Model baru dari layanan referensi sebagai upaya kompensasi penurunan layanan referensi tatap muka. Beberapa perpustakaan mulai meninggalkan mejainformasidanlebih memilih perpustakaan lainnya dengan menggunakan telepon, surat elektronik, chat dan IM. Perpustakaan lainnya menggabungkan layanan perpustakaan dalam satu tempat yang terdiri dari layanan referensi, layanan fotokopi, dan bantuan dengan komputasi.

\section{F. Layanan Referensi di Pusat Perpustakaan UIN Syarif Hidayatullah Jakarta}

\section{1) Jumlah Koleksi Referensi}

Sumber-sumber referensi yang dikoleksi Pusat Perpustakaan UIN Syarif Hidayatullah antaralain: sumberbiografi, bibliografi, sumber geografi, indeks, abstrak, direktori, kamus, ensiklopedia, almanak, dan sumber-sumber referensi lainnya. Jumlah koleksi yang ada di layanan referensi adalah 2738 judul, yang terdiri dari 599 judul koleksi referensi Islam dan 2139 judul koleksi referensi umum.

Beberapa koleksi referensi berbahasa arab antara lain:

a. Mu’jam al-udaba' au irsyad al-arib ila maghfirah al-adib

b. al-Mausu'ah al-'Arabiyyah

c. Mu'jam al-hadharah al-mashriyah alqadimah

d. Mu’jam al-mufahras

e. Atlas al-Quran

f. Fahrasu Ahadits

g. Athlas al-hadits al-Nabawi

h. al-Qamus al-fiqhiyah lughatan wa istilahan

i. Mausu'ah fiqh 'Abdullah ibn 'Umar: 'ashr wa hayatuh

j. Mu'jam fiqh al-salaf 'itratan wa shahabatan wa tabi'in

k. Mu'jam al ulama al-Araby

1. Al-alam: qamus tarjin li ashar al-rijal wanisa'i min al-'arbi wa al-munta'aribin wa al-mustasyirqin

2) Jenis-jenis Layanan Referensi yang ditawarkan

Pusat Perpustakaan UIN Syarif
Hidayatullah Jakarta memiliki dua jenis layanan referensi yaitu layanan referensi koleksi Islam dan layanan referensi koleksi umum. Layanan referensi terletak di lantai 5 gedung Pusat Perpustakaan UIN Syarif Hidayatullah Jakarta.

\section{3) Prosedur pemberian Layanan Referensi}

Koleksi referensi tidak boleh dipinjamkan melainkan hanya boleh dibaca ditempat dan bagi anggota yang sangat memerlukan informasi dari koleksi referensi maka diperbolehkan meminjam koleksi referensi tersebut untuk difotokopi dalam waktu maksimal satu jam, dengan syarat mengisi formulir yang disediakan dan meninggalkan kartu anggota/kartu identitas yang masih berlaku.

Tentunya terdapat perbedaan perlakuan terhadap kedua jenis layanan referensi tersebut. Perbedaan mencolok lebih kepada penguasaan bahasa. Untuk koleksi layanan referensi Islam yang koleksinya menggunakan Bahasa Arab maka agar pustakawan referensi dapat memberikan informasi kepada pemustaka, pustakawan referensinya harus menguasai Bahasa Arab.

Pustakawan referensi di Pusat Perpustakaan UIN Syarif Hidayatullah Jakarta hanya ada satu orang saja. Namun bukan berarti semua pertanyaan referensi ditangani oleh satu orang saja. Bagi pustakawan lainnya tentunya dipersilahkan untuk dapat membantu menjawab pertanyaan referensi. Walaupun tidak ada papan informasi yang menjelaskan keberadaan pustakawan referensi, pemustaka sudah mengetahui bahwa pustakawan yang menempati lantai 5 (ruang layanan referensi) akan membantu menjawab pertanyaan referensi.

Hingga saat ini pelayanan referensi di Pusat Perpustakaan UIN Syarif Hidayatullah Jakarta masih bersifat manual. Layanan referensi baru sebatas bertemu langsung antara pemustaka dan pustakawan. Belum ada fasilitas berupa call centre atau e-mail yang bisa digunakan pemustaka sebagai sarana bertanya kepada pustakawan referen.

Kegiatan pustakawan referensipun hanya sebatas memberitahukan informasi letak koleksi referensi yang sedang diperlukan 
oleh pemustaka. Selanjutnya pemustaka sendiri yang akan mencari informasi yang diperlukannya tersebut. Kegiatan seperti ini dikenal dengan penelusuran informasi.

\section{G. Kendala yang Dihadapi Pustakawan Referensi}

Kendala yang terjadi pada pustakawan referensi di Pusat Perpustakaan UIN Syarif Hidayatullah Jakarta saat ini adalah penguasaan bahasa asing. Terutama dalam penggunaan koleksi kitab-kitab berbahasa Arab. Misalkan saja ketika ada pemustaka yang bertanya mengenai dalil-dalil hadits atas suatu hal maka setidaknya pustakawan referensi harus memahami bahasa Arab dari hal yang dimaksud pemustaka tersebut. Setelah mengetahui bahasa Arabnya selanjutnya pustakawan mengarahkan pemustaka tersebut ke rak koleksi kitabkitab hadits. Dari beberapa kitab-kitab hadits diperlukan pula pengetahuan cara pencarian informasinya karena penelusuran hadis harus ke sumber aslinya.

(Wanda Listiani, 2007) Persoalan dalam layanan referensi bukanlah dalam menemukan sumber-sumber yang cukup, melainkan dalam memilih sumber-sumber yang paling tepat dari antara banyak sumber potensial lainnya, sehingga jaminan kualitas menjadi prioritas utama bagi setiap perpustakaan, yang pada saat ini khususnya dijadikan sebagai tolok ukur keunggulan daya saing lembaga. Layanan yang berkualitas adalah upaya maksimal yang mampu diberikan oleh pustakawan dari suatu jasa layanan untuk memenuhi harapan dan kebutuhan pemakai sehingga tercapai suatu kepuasaan. Terdapat empat hal untuk mengukur kualitas layanan referensi yaitu ketepatan layanan, layanan yang ramah serta selalu siap menolong, kecepatan layanan, dan kemampuan pustakawan untuk cepat tanggap dalam menghadapi masalah yang timbul dan terhadap keluhan yang disampaikan pengguna.

(Lasi dan Eko Setiawan, 2012) Kepuasan pengguna perpustakaan berkaitan erat dengan kualitas layanan, yang dapat memberikan dorongan kepada pengguna untuk menjalin hubungan yang kuat dengan perpustakaan.
Dengan terjalinnya hubungan, diharapkan perpustakaan dapat memahami harapan dan kebutuhan pengguna, sehingga meningkatkan kepuasan pengguna dengan memaksimalkan pengalaman yang menyenangkan dan meminimalkan atau meniadakan pengalaman yang kurang menyenangkan.

Layanan perpustakaan yang tidak dapat memuaskan pengguna akan menghadapi masalahyangkompleks karena penggunayang tidak puas akan menyampaikan pengalaman buruknya kepada orang lain. Oleh karena itu, perpustakaan harus mampu merencanakan, mengorganisasikan, mengimplementasikan, dan mengendalikan kualitas layanan dengan baik sehingga layanan yang diberikan dapat memuaskan pengguna.

Perpustakaan perlu melakukan pemantauan dan pengukuran kepuasan pengguna. Melalui pemantauan dan pengukuran kepuasan pengguna, umpan balik dan masukan dari pengguna dapat diperoleh untuk pengembangan strategi dan implementasi peningkatan kepuasan pengguna perpustakaan.

Memberikan jawaban pada pertanyaan yang diajukan pemustaka tidak selalu berjalan lancar. Beberapa hal yang menghambat kelancaran berakar dari pustakawan referensi sendiri. Tidak jarang seorang pustakawan memberikan informasi yang salah karena sudah kadaluwarsa, tentu saja tidak akurat.

\section{H. Penutup}

Layanan referensi sebagai bagian dari layanan perpustakaan akan menjadi layanan yang diminati oleh pemustaka ketika layanan yang diberikan pustakawan referensi dapat menjawab pertanyaan dan dapat memenuhi kebutuhan informasi yang diajukan pemustaka. Terlebih Pusat Perpustakaan UIN Syarif Hidayatullah Jakarta yang menjadi jantungnya perguruan tinggi harus mempersiapkan pustakawan referensi yang kaya akan pengetahuan informasi dari sumber-sumber koleksi yang dilayaninya.

Dengan berkembangnya teknologi 
informasi, sebaiknya pustakawan referensi tidak menyerah begitu saja ketika informasi yang dibutuhkan pemustaka tidak ditemukan dalam perpustakaan. Pustakawan referensi dapat memanfaatkan internet atau bertanya langsung ke perpustakaan atau pusat informasi lainnya.

\section{Daftar Pustaka}

Widyawan, Rosa, Pelayanan Referensi: Berawal dari Senyuman, Bandung: Bahtera Ilmu, 2012

Wanda Listiani, Mengukur Kualitas Layanan Referensi. Fihris Vol. II No. 1 Januari - Juni 2007

Hildawati Almah, 2013), Pengembangan Layanan Referensi di Perpustakaan (Antara Harapan dan Kenyataan), Jurnal Iqra' Vol. 07 No.01 Mei, 2013

(Lasi Dan Eko Setiawan, 2012), Analisis Kepuasan Pengguna Layanan Referensi Melalui E-Mail Di Perpustakaan Universitas Surabaya, Jurnal Perpustakaan Pertanian, Vol. 21, No. 1 April 2012

Suharyanto, Glosarium Istilah Perpustakaan, Pare: FAM Publishing, 2014

World Encyclopedia of Library and Information Service, Chicago: American Library Association, 1993

Sulistio Basuki, Pengantar Ilmu Perpustakaan, Jakarta: Gramedia, 1993

Cassel, Kay Ann and Uma Hiremath, Reference and Information Services in the $21^{\text {st }}$ Century, London: Neal-Schuman Publishing, 2011 